Research Article

\title{
Research on College English Multimedia Teaching Model Driven by Wireless Communication Network Environment
}

\author{
Xinguo $\mathrm{Li}^{1}$ and Hua Zhang $\mathbb{D}^{2}$ \\ ${ }^{1}$ School of Foreign Studies, Anhui Polytechnic University, Wuhu Anhui 241000, China \\ ${ }^{2}$ Foreign Language School, Weifang University, Weifang Shandong 261061, China
}

Correspondence should be addressed to Hua Zhang; zhanghua198316@126.com

Received 18 September 2021; Accepted 19 October 2021; Published 9 November 2021

Academic Editor: Guolong Shi

Copyright (C) 2021 Xinguo Li and Hua Zhang. This is an open access article distributed under the Creative Commons Attribution License, which permits unrestricted use, distribution, and reproduction in any medium, provided the original work is properly cited.

\begin{abstract}
English teaching has also gradually introduced computer network-assisted teaching methods. Compared with other subjects, English teaching has many constraints, including lower teacher-student interaction time, lack of English speaking training environment, single learning method, and other problems leading to the phenomenon that English teaching tends to emphasize theory but not practice. In terms of the current practical situation, the development and research of computer network multimedia courses are still far from meeting the actual needs of English network teaching. English network teaching mainly involves the transmission and use of video streams on the network, but the current video stream transmission conditions are not very ideal. Therefore, this paper focuses on the practical development of computer-assisted teaching in English teaching based on the browser/server (B/S) architecture mode of network multimedia teaching system, so that the teaching reform of English network courses can be further improved and developed. The research content of this paper is based on the development technology of the B/S mode, theoretical study and research on the production method of the English network teaching system, and practical evaluation and development application of this teaching system. A comparison of the educational effects of computer network education models and traditional education models is carried out to determine the implementation and effectiveness of web-based English multimedia education systems. Based on a web browser-based network education model, the Internet is used as a means of transmitting media education content with synchronised English and playback lessons as well as related online tests and online question and answer sessions on the Internet, enabling timely and efficient educational activities. The teaching system is also evaluated and applied. The research results show that the network multimedia teaching system provides a variety of forms of materials, making the original more abstract content a more vivid image and concrete. Changing the original traditional teaching mode of English makes students' English learning change from simple memory to concrete understanding; increasing students' initiative to information not only improves the utilization of time but also changes the monotonous information exchange from teachers to students, providing a large number of English environment materials, which is conducive to students' oral practice and promotes the successful completion of teaching tasks.
\end{abstract}

\section{Introduction}

In today's rapid development of science and technology, the multimedia network is rapidly being developed in the practice of language education reform, and methods and educational outcomes of foreign language teaching attract attention [1]. The new curriculum requirements will result in the State Department of Education advocating a reform of the education system in line with the development of current classes and obliging higher education institutions to change traditional education by improving the new education system. Teacher students are passively adopting learning practices, which is even more important, in educational means for the full use of computer networks and multimedia technology [2]. Until now, teaching methods in English education have been relatively simple, mainly in teachers' classrooms, and pupils have used passive learning methods [3]. In the context of the reform of the new education system, English teaching, 
supported by computer information technology and network technology as multimedia technology, is no longer limited in time and place in light of advanced technologies and diverse information, and pupils are proposed: to be able to develop according to their unique characteristics towards independent learning [4]. Students can do learning tasks under web-based conditions with guidance and discipline [5]. Through appropriate teacher guidance and limitations, learners develop positive learning habits and eventually switch to fully personalized learning for their students [6].

In general, this should be advantageous in order to improve the efficiency and quality of foreign language learning. Research shows that communication and interactive language environments are more useful for learning foreign languages than in a language environment focused on learning the language structure and grammatical rules, as opposed to the one-sided communication environment that learners do. You do not have to answer. Instead, linguistic knowledge is easily and efficiently absorbed [7]. In this context, the use of multimedia education systems for English tutorials has become even more urgent. Only multimedia education systems on the Internet can compensate for the lack of development in English education. An important factor in the design and development of distance learning approaches is that software interactivity must be taken into account. There are many technologies that can be used to improve interactivity. This overcomes the isolation that pupils experience when learning from a distance [8]. As a leading web-based educational and learning research guru, Berge offers a broad definition of interaction in a distance learning environment [9]. "Interaction is the mutual communication between two or more people in a learning environment and the development of learning tasks or interpersonal relationships, so that interaction is an opportunity for teachers and students to get feedback on information and adaptive learning activities." The theoretical and practical approach to English teaching, which uses computer-Internet multimedia systems, is to develop a tutorial guide that complements the teaching outside the curriculum [10]. The Internet English Multimedia System not only allows the diffusion of theoretical knowledge compared to conventional teaching methods but also allows an efficient reading and checking of linguistic knowledge and provides an operational platform for highly effective online communication methods. It is very simple [11]. In addition, the availability of a variety of language learning materials increases the completeness of language learning and eliminates the monotony and boredom of language learning. Audio lessons mainly involve scenario simulations, the viewing of films, and listening to music. The content of the network's multimedia learning platform is reusable and reduces the workload and time of teachers in the teaching and knowledge transfer process, improving the efficiency of teachers [12]. After entering these thankful research and speech training phases, the students can quickly apply the expressions learned in the auditory evaluation in speech communication and quickly improve their level [13].

Compared with traditional teaching, multimedia network teaching is rich and diverse. Students receive language stimulation in visual and auditory aspects, and compared with the traditional one-way learning mode of a single duck and filler, online multimedia teaching presents a two-way teaching mode with interaction and feedback, in which students increase their selectivity and can learn independently and actively on demand according to their personal needs and preferences, which improves students' motivation to learn the language and ensures the increases in students' motivation and ensures efficient learning. The user interface communicates only with the web server layer and not directly with the data access layer, while the web server layer takes turns communicating with the user interface layer and the data access layer. In this architecture, the user-side accessor submits a request for browsing the database to the web server based on the hypertext model. In the process of selfselection, students are not only receptive to new language vocabulary but also interested in imitating it, and this active imitation greatly increases the desire for subsequent learning and enhances the continuity of language learning. Traditional teaching relies mainly on the teacher's mechanical questioning and one-sided dictation, which makes it difficult to mobilize students' subjective initiative. For students in the process of learning English courses, the vast majority of the knowledge in the classroom teaching cannot be immediately mastered but also need a lot of time outside of class to accept digestion; English online courses in all courses can be achieved on-demand; students can relearn and consolidate each link for their own situation and also according to their own flexible learning time, to achieve personalized learning goals of students. Therefore, the author tries to improve the teaching process of English and researches and studies the Internet English multimedia teaching system based on the $\mathrm{B} / \mathrm{S}$ model.

\section{Related Work}

With the development and support of computer networks and multimedia technologies, universities in the country have made more attempts to reform English courses, and these attempts have changed the form of English education [14]. And under the new English curriculum standards, the educational problems of traditional educational models increasingly hinder the improvement of the quality of education, and with the continuous development of information and communication and the growing maturity of computer networking technology, more and more language teaching is taking place at all levels and in all types of language teaching using networking as a form of education. The multimedia network education system can extend the scope of activity and the practical scope of English education. Next, teaching methods and methods were greatly improved and developed, and many features such as diversity and flexibility emerged [15]. In the near future, networked and multimedia technology education is expected to be an important and integral part of the language learning process. Network training in English cannot be carried out properly without the support of network technology. With the deepening of technology research and application, many higher education institutions, national research institutes, and networked 
technologies have amassed research on networking education systems and networking software. By developing webbased educational standards and providing web-based course system services, we have been able to promote the practical application of web-based education [16]. To date, remote web teachers have more media technology support available. The online course distribution system is widespread in online education.

A large number of web-based course management tools have emerged, such as Blackboard, WebCT, LearningSpace, TopClass, WebCourse, and First Class, to assist course designers or instructors in creating complex web-based learning environments that include management of instructional staff, course design, and student evaluation, among many aspects. For example, in the Blackboard and WebCT online course design environments, all interactions with online courseware occur through a web browser, and both provide both synchronous and asynchronous interactions between students and faculty [17]. WebCT is mainly used for the online development of instructional courses and also for publishing instructional course content on the web. It establishes close interactivity between a wide range of instructors and students, and it has a rich template and wizard mechanism that allows instructors who do not know programming to still enjoy the benefits of computer technology for teaching and developing web-based course projects with an instructor's personal touch. It runs on UNIX systems and has a number of features such as security controls, administration, and data backup [18]. The "Digital Collections" project created a website that brought together and digitized school, museum, and corporate materials, with a considerable amount of material in various formats, from human history to technological developments [19]. The project has made a very significant difference not only in terms of access to new media but also in terms of the renewal of ideas. Similarly, the UK has invested heavily in the National Learning Network project, which has created an overall network of social resources for learning and has played an important role in the reform of information technology in education in the country; at the same time, other European countries have created similar online education systems. At the same time, other European countries have also created similar online education systems.

In China, the research and practical application of network teaching systems started relatively late, and the development only just started in the 1990s, but the development was relatively rapid and the research and development activities were relatively active. 1995 was the year when GERNET, the first computer network covering the whole country, was put into use, and it was only after that that the research work on network distance education was started in China on this basis, and greater results were achieved [20]. The limitations of the construction of network multimedia are also one of its shortcomings, for the special language teaching needs require more hardware and storage equipment support, and because the language has the characteristics of rapid update, it is not easy to accumulate and maintain the multimedia database, so in practice, in the task of building a network English multimedia system, often the quantity and quality cannot meet the requirements. The overall test performance of the system is affected, especially the network audio and video streaming network transmission problems, which are also the current constraints on the rapid development of a network teaching system.

\section{Multimedia Teaching System with Wireless Communication Network}

3.1. Web-Based B/S Three-Tier Architecture. The B/S model is chosen for the development of this network English multimedia teaching system platform. With the development of computer technology, the traditional host/terminal cannot meet the current requirements of information sharing, so the $\mathrm{B} / \mathrm{S}$ model was born, which is the so-called browser/server structure. The servers in turn can connect to database servers using different methods, resulting in much of the data actually being stored in the database servers. The client does not usually need any user program outside the web browser and just download the program from the server to the local execution, and if it encounters database-related instructions during the download, the server will pass them to the database server for interpretation and execution, and then return them to the server, and then, the server will return them to the user. The first layer of the B/S 3-tier architecture is the user interface layer, which represents the client side of the application. The user's service is installed mainly on the web client or Windows client, and its role is mainly to give acceptance to the user's request and then return data to the client application to provide access. This is the level where the user directly contacts the software system and is dynamically generated with the support of the second layer (web server layer) and the third layer (data layer). The second layer is the web server layer, which is the bridge between the user interface layer and the data layer. It plays a role in the 3-layer architecture and is responsible for the operations of the data layer, i.e., putting together the operations of the data layer.

The purpose is to enable the logic of the underlying storage of the data access layer to be combined into business rules. The third layer is the data layer, which is the layer of manipulation of raw data, and the atomicity of the functions of the data access layer is ensured in the implementation of this layer. The data layer is the basis for the proper operation of the software system, and it can be said that the information provided by the data layer is used for the generation of each dynamic mesh of the system. Depending on the different uses of the data information, it can be divided into different categories and then stored in the appropriate database in an orderly manner. When users adopt this system, they must first browse the user database in order to clarify the actual identity of the users and the rights they have. The network architecture of a representative $\mathrm{B} / \mathrm{S}$ architecture using the system is shown in Figure 1.

The user interface communicates only with the web server layer and not directly with the data access layer, while the web server layer takes turns communicating with the user interface layer and the data access layer. In this architecture, the user-side accessor submits a request for 

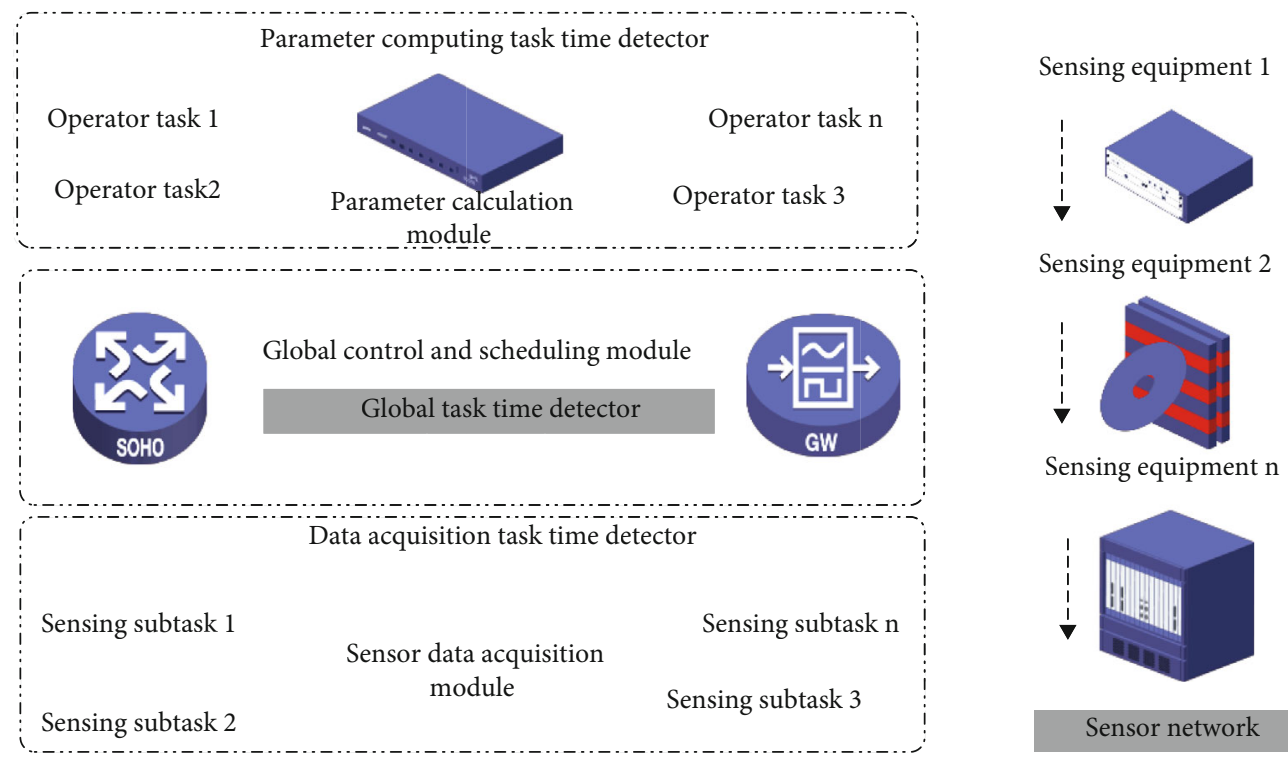

FIGURE 1: Network architecture of the B/S architecture using the system.

browsing the database to the web server based on the hypertext model. The data communication process in the $\mathrm{B} / \mathrm{S}$ architecture is shown in Figure 2. Generally speaking, it is more convenient to use JSP than Servlet, because JSP can separate the code and HTML type language, help the designer of the code and the designer of the page to separate, and improve the efficiency of the development of the system.

The advantages of $\mathrm{B} / \mathrm{S}$ architecture are the following.

(i) Optimization of the client. Only the browser needs to be installed, which not only reduces the burden on the client but also saves disk space and memory on the client computer, making it user-friendly as well as technically feasible

(ii) Very easy to maintain. The application system will benefit greatly in terms of system maintenance cost by requiring only updates to the software on the server side when performing data installation and upgrades. It makes the upgrade cost of the whole system to be reduced

(iii) Reducing the load on the client terminal. Each time when the user is using the web port, the connection between the two is established, and when there is no response to any data, the client's connection will be cancelled, making the most efficient use of resources

(iv) Implementing off-site tour operations for users. The tool required for the use of this network multimedia teaching system is mainly a personal host that we commonly use, and users can use the software system under the $\mathrm{B} / \mathrm{S}$ structure when logging in offsite, as long as they can log in to the network using the tourer

(v) The B/S architecture making the system more scalable for subsequent extensions. Because of the platform-independent nature of the web, workgroups in this architecture can be extended at will, from the workgroup level of a single server with a few users to large-scale systems with thousands of users

3.2. Multimedia Teaching System Design Model. The J2EE platform uses a multitier distributed environment that includes starting, deploying, and executing applications. J2EE applications are the platform for implementing various server-side technologies to enter the realm of multitier component architectures. J2EE is the middle-tier server in a three-tier architecture. The $\mathrm{B} / \mathrm{S}$ architecture after using J2EE is shown in Figure 3. At present, most of the higher education institutions have scholars conducting theoretical and practical researches on network distance education, and there are also teachers who are organizing their efforts to work on the development of using a network course system; on the basis of which, all of them have established a network multimedia teaching system on the basis of campus network and extended this service to the society to realize the sharing of educational resources.

In the use of servers, containers play the role of middleware, such as the web container that provides a running condition for the JSP; before the actual running of J2EE programs, the components of these programs and J2EE use the program itself to fix the settings of these containers, such as transaction management and security, while the container also provides components of the technical standard API of the Java programming language that simplifies application development and also maintains a separate software component and broad portability. Deploying components in containers provides a working environment in which distributed development and access to provided component interactions are very complex. Containers have the ability to provide access to methods in other components without requiring the component 


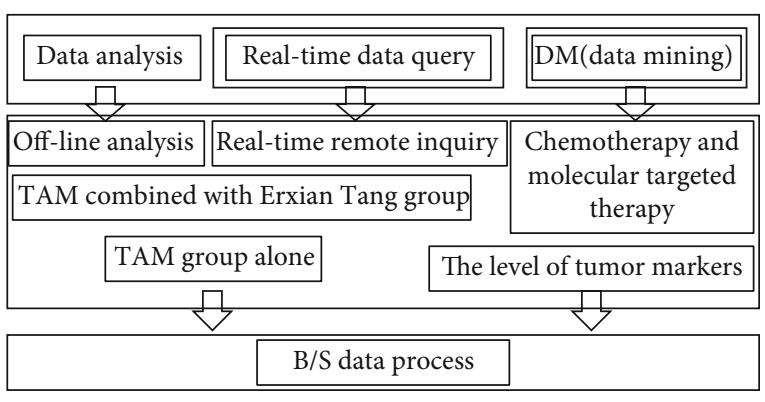

Figure 2: Data communication process in B/S structure.

developer to write the appropriate invocation code; this capability of containers is important for simplifying distributed development. J2EE will compose a complete enterprise application, incorporating the needs of different parts into different containers, the number of components each container contains, and the various services/APIs that individual components can use with various J2EE.

NET is a Microsoft companion product that is part of the enterprise strategy, and the framework is a set of class library sets used to help develop applications. The VS2005 development platform requires the support of such library sets, and programs developed with VS2005 require the support of such library sets. ASP.NET is a Microsoft technology that enables scripts embedded in web pages to be executed by an Internet server. It refers to Active Server Pages, a program that runs in IIS. J2EE is the standard for programmers writing software, and both products have their own characteristics, each with its own advantages. J2EE has the advantage of being able to integrate with existing systems, while NET has a disadvantage in this respect. J2EE is able to integrate existing product applications at scale through JCA. The Microsoft NET solution is a complete set of applications and research on Windows systems, and the development of Javarelated technologies has been affected by the fact that NET is not ideal at the Java application level. At the application level, both are capable of meeting the needs of enterpriseclass applications. But essentially, I/O processing and thread scheduling should be handled by the underlying hardware and system operations. Because J2EE can support a wide range of hardware and operating systems, it has more advantages than the NET technology. The I/O processing and thread scheduling capabilities of some mainframe computers, for example, far exceed the capabilities of any other machine. The fact that J2EE can only run on these mainframe computers and not on .NET is a good indicator that J2EE is superior to .NET technology in this respect.

3.3. Use of Multimedia Models within the Web System. We can divide the objects of use into three types: the first one is the object that includes commercial data and specifications; the second one is the object that is displayed, and the other one is the one that monitors the commercial object after obtaining the application to satisfy the application. The presentation of this object should be changed often, like the arrangement, structure, and color of the page. However, the business specification and data are relatively stable. There- fore, the object that represents the display, i.e., View, should be changed often, and the object that represents the business specification and data, i.e., Model, is also stable, but the object that represents the monitoring, i.e., Controller, is the most stable. Generally speaking, after these systems are published, the object is monitored by the designers of the HTML and JSP or by the supervisors of the system and the visual designers. Monitoring objects are implemented using development designers, database administrators, and industry domain experts who work together on business data objects and business rule objects. The client or web level is responsible for monitoring the presentation logic, which can be a JSP or a Servlet, or a language in the form of HTML. However, in reality, JSP can satisfy all the roles that Servlet can satisfy, and JSP will also become Servlet in the end, and there are objects related to the monitoring of the system at each level to coordinate multilayer actions. Objects containing business rules and data are stored in the EJB layer (EJB-centric model) or web layer (web-centric model).

View is the representation of the system, which is at the web level. It usually consists of a Java Bean, a Custom Tag, and a JSP; a JSP can be used to shape the content of a web page in a fluid manner, while a Custom Tag facilitates the use of Java Beans and encapsulates the logic of the representation, making it more useful for modularity and reuse. Some well-designed Custom Tags can be used in several JSP applications or even in the same system multiple times. The data in the Java Bean is updated by the Model and Monitor objects. Generally speaking, you should first design all the pages that may appear in the system, that is, all the content that users will see when they go to operate the system. This content consists of three domains: the public domain, the dynamic change domain, and the static domain. We can form a single JSP for the content in the public domain through a module and form a JSP or HTML for the content that should be changed through a module of JSP to output different domains. In addition, there is still a problem worth thinking about, that is, the selection of the page. After the system has finished processing the user's application, the module that is displayed is the one that has been adjusted by itself. Therefore, it is possible to think about the concept of storing all pages in a single aggregated file, such as a Java file or a text file. Since it should be expected that the file that defines the page may change in the future, the best option is to use a text-based file, such as an XML file, if it is changed and does not have to be compiled again. The system can map to one of the result pages according to the address and parameters of the URL imported by the user, but it may still select different pages according to the result of the action, so there should be an XML, and if a URL application will have different results, the XML should indicate if there is to be a monitoring and different destination of the corresponding page.

\section{Testing of Web-Based Multimedia Teaching Systems}

The design of functional test cases in this subsection uses the boundary value test method; this network teaching system 


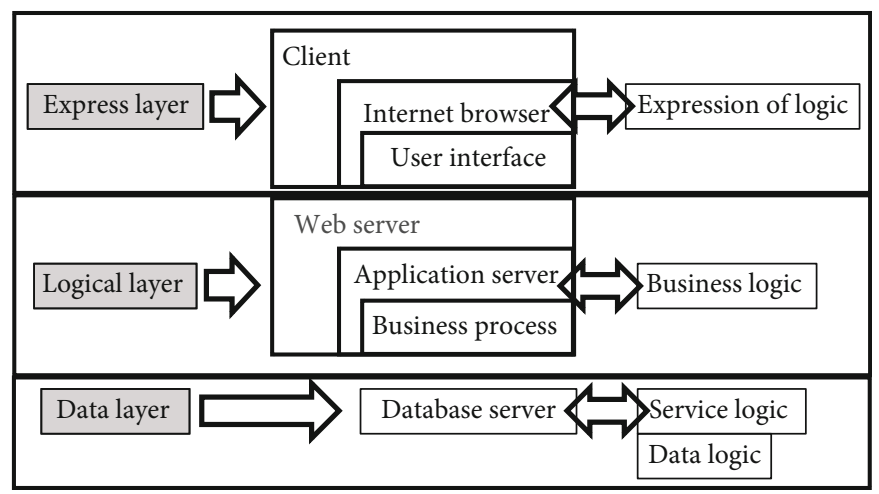

Figure 3: B/S structure after using J2EE.

involves a large number of characters and numbers of length problem and needs to use the boundary value method for testing. The scope of testing of this system is aimed at the main business functions of each unit of the main module of this multimedia teaching system. This is to check whether our system meets the requirements and to find out the difference between the actual results and the expected results. The objective of these tests is to determine whether the data is properly accepted, processed, and retrieved and whether the intermediate logic business rules are correctly implemented, and if so, to introduce them, and if not, to determine whether they are caused by subjective reasons, etc. After eliminating the subjective factors, we should record the objects that do not pass the test objectives for subsequent modifications. This type of testing is based on a black box testing approach where the application and its internal processes are verified by interacting with the application through a graphical user interface and analyzing the output, as shown in Figure 4 . The following lists the testing process of the relevant test objects of each module, such as testing the functions of the test bank system including test entry, test modification, test deletion, test retrieval, manual paper issuing, automatic paper issuing, and user name and password setting functions work properly, exercise module testing, view courseware module testing, self-test module testing, course scheduling and news announcement testing, and other subunit testing of each module. Here, we will not list each module and submodule one by one.

General performance testing includes stress/load testing, the number of people who can access the page at the same time, testing the system under normal and abnormal load of the system, and testing the ability of the system to run the software properly under abnormal conditions. If the core modules of the system are set, such as user registration and user login in the public module, self-test exercises in the student module, electronic school files, schedules, and question and answer in the teacher module, the modules are tested for deadlocks by stress testing the modules, as shown in Figure 5. The test of network performance, for the average user, is the initial criterion for the connection speed used by the online teaching system. If the system response time is too long, in the effective teaching time, in addition to affecting the overall teaching effect, more importantly, preventing the smooth running of the teaching process, the teacher in the use of the process will consider abandoning the network teaching system. Also, when the page response speed is too slow, it may lead to data loss or the need to log in again.

The system's ability is tested to run under different environmental stresses, specifically to test the running ability of the network multimedia language teaching system under different operating systems, the availability of functions under different browser versions and the normal use of the network, etc., and to test the display performance of Windows under different resolutions. The main interface link test, the interface as a whole, and the interface elements of various indicators, as shown in Figure 6, test whether the user's interface can be customized, as far as possible, to find and correct the errors in the interface design of the network multimedia system and to ensure that the entire software development process is of high quality and improve the interface friendliness to the end customers of the system. The ability of the system is tested to run the software normally under abnormal conditions, i.e., abnormally under the browser, resolution, and operating system environment specified in the description document of this web multimedia language teaching system.

The main test objects are the individual unit functions under each major module. The test plan has to follow certain guidelines in order to ensure a smooth test plan and smooth closure of this teaching system platform. As a test entry guideline for this teaching system, after the module under test of this language teaching system platform is compiled and passed, then the testers can start the system testing. As a guideline for stopping the testing process of this teaching platform, as a guideline for unit testing, testing can be stopped when the module under test meets the intended objectives of the module of the web-based multimedia language teaching system, and the testing meets the coverage requirements, when all defects are modified and the regression test is passed. As an integration test rollout criterion, when the student module, teacher module, administrator module, and public module all meet all the predefined requirements of the requirement specification, and the test coverage of each module meets the specified requirements, as shown in Figure 7, all permissions are modified and verified, the integration test is submitted and approved, and the integration test can be exited. As an exit guideline for system 


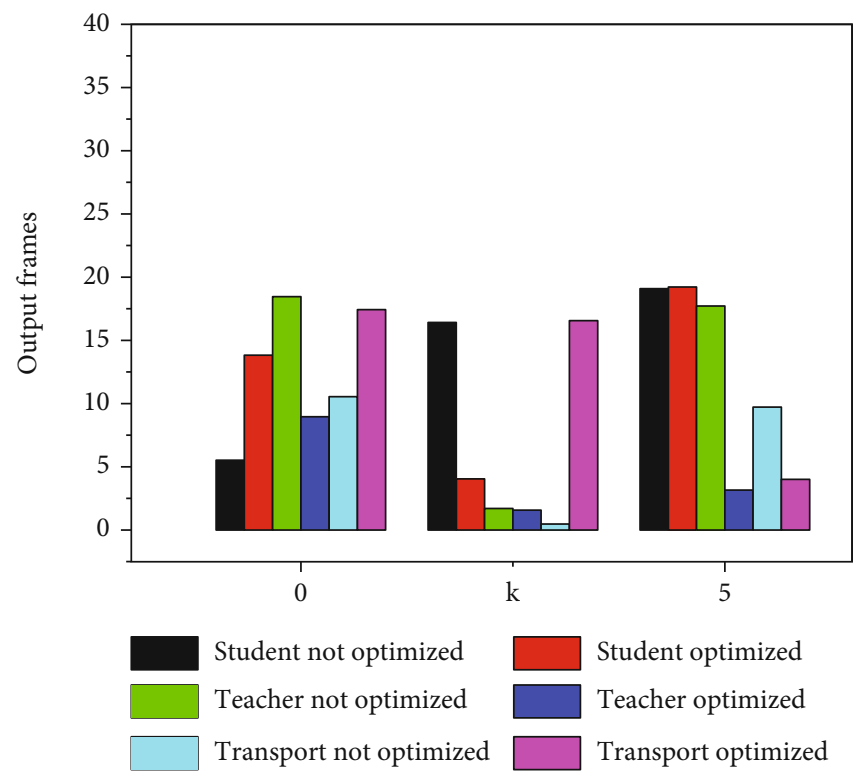

Figure 4: Output of user graphics.

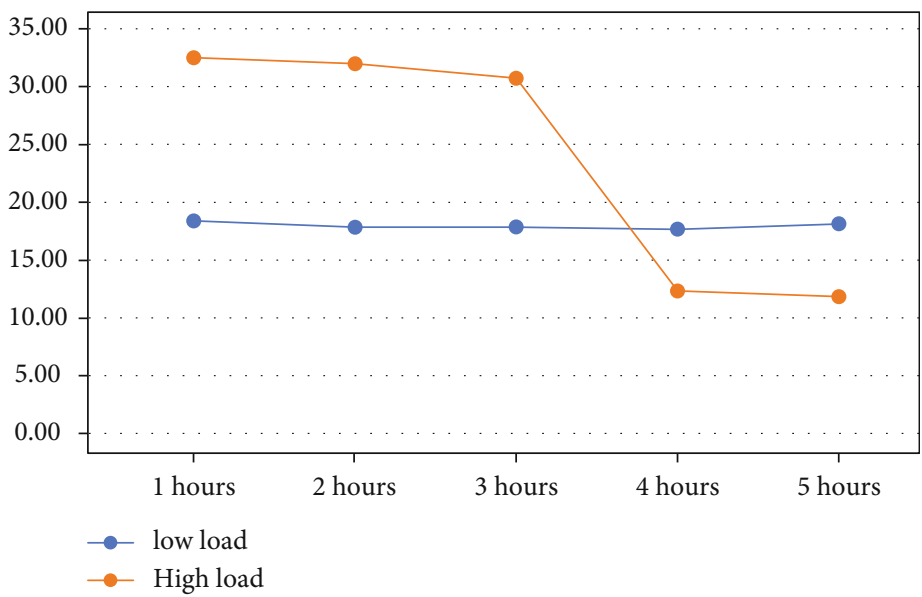

Figure 5: Module stress test.

testing, when this web-based multimedia language teaching system is integrated, system testing meets certain coverage requirements, all defects are modified and validated, system testing is submitted and approved, and system testing can be exited. That is, acceptance testing can be performed, and if the acceptance criteria are met, the acceptance operation can be performed. The blocking criterion for the testing process of this web-based teaching platform is that, as a unit test blocking criterion, when the internal construction of the unit is not fully developed, such as the module under test is the student module, and a component under the student module such as the address book editing interface is not developed, the unit test is stopped in the middle. As an integration test blocking criterion, if the integrated system interface is incompletely developed, such as the database stored procedure interface between the module under test and the student module and the teacher module is incompletely designed, or the interface is incomplete and cannot be inte- grated, then the integration test is blocked and the integration test is stopped in the middle. System testing is hindered by the guidelines, such as when the system operation crashes.

Due to the complexity of the system increasing the tediousness of testing, limited to the length of the paper, this testing section mainly describes the main typical units under the main several modules of the functional testing of this web-based multimedia teaching system, for the other units listed testing situation as described above in this paper. The design of functional test cases in this subsection uses the boundary value test method; this network teaching system involves a large number of characters and numbers of length problem, needs to use the boundary value method for testing, and also used the equivalence class method; this network teaching system uses name, numbers, English, and symbols and uses the equivalence class method to simplify the test, as shown in Figure 8. In terms of test case design, 

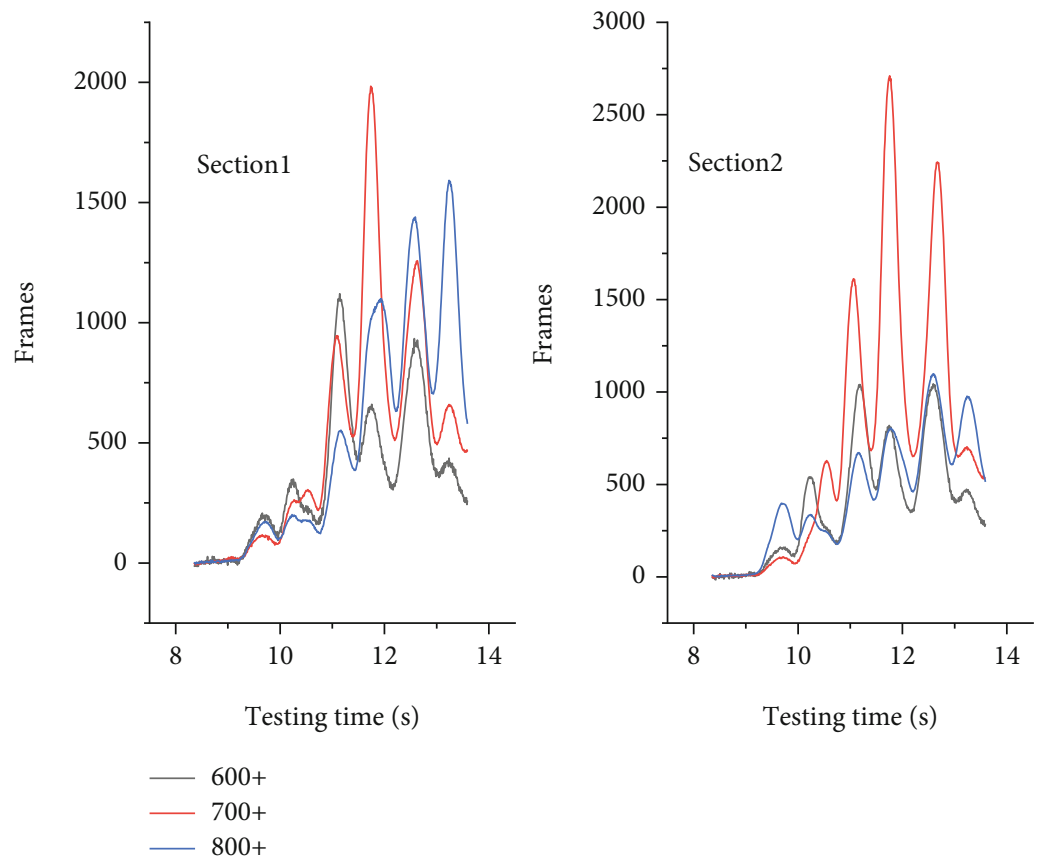

FIGURE 6: Overall interface fluency test.

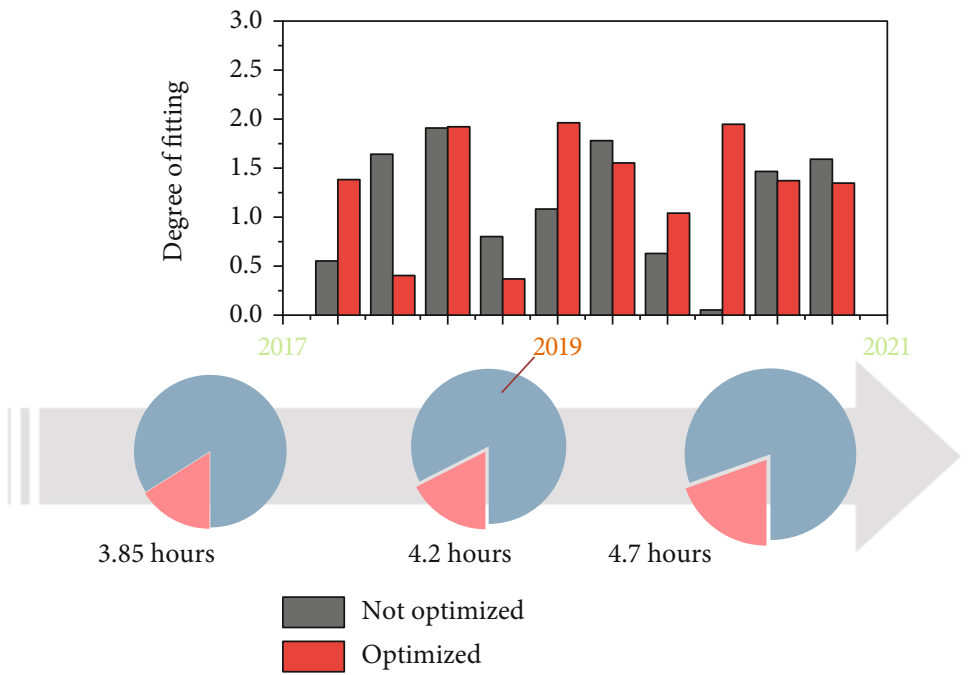

Figure 7: Integration test coverage.

we used use case-based test cases. We borrowed the understanding of testing from the teacher in the software testing class: software testing is a very apprehensive process in the software development process. It is easy to understand why this is so. The development of this web-based teaching system is a highly human activity, and errors in the software are inevitable due to the limitations of the authors' abilities and efforts. The whole process of developing this webbased multimedia language teaching system, from requirement analysis to design to writing code, step by step, is the crystallization of our wisdom; however, with the continuous testing of this system, we will find ourselves in the develop- ment process of various problems, such as the design stage of the multimedia system, in addition to the registered users, should we set up another visitor module for scalability, such as the writing code phase, should the code increase reusability, which is an improvement not only for the development phase but also for the testing phase which will save testing resources as well as reduce workload, thus increasing testing efficiency, etc. Whether it is the unreasonable requirement stage or the imperfect design stage or the logic problem when writing code, etc., every bug found is a test of your self-confidence, and you need to remind yourself all the time that many places are not as simple as you think, and even if the development process is 


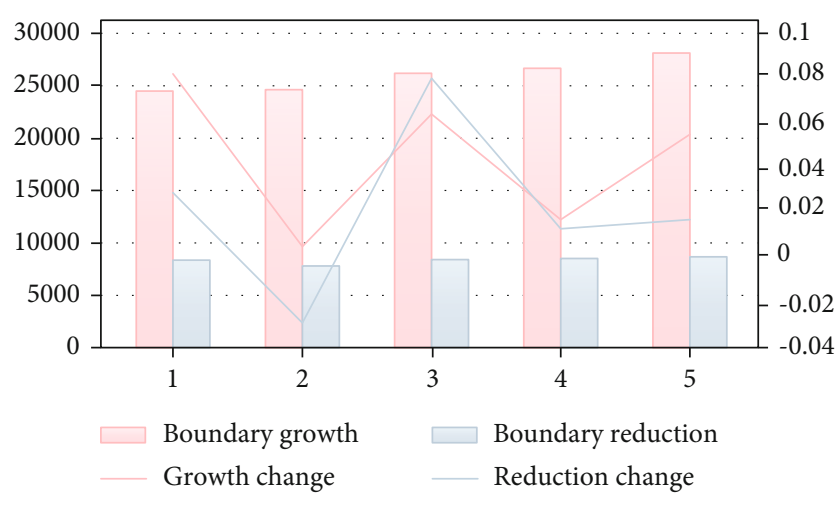

FIgURe 8: System boundary tests.

well thought out, there will always be mistakes, and this is exactly why software testing must exist.

The system is designed to take advantage of the EJB2,0 standard in designing the logic layer of the business. EJB is part of J2EE, which is not a product from the point of view of technical specifications, but a description of the standards to be solved for building application components. There are two main interfaces in Javax.ejb: one is home and the other is remote. Clients can use these two interfaces when accessing enterprise beans. The remote interface provides a specific method of operation, for instance, operations, and the client can access the interface only after the method of operation is determined. The home interface has other functions, such as creating an EBJ, locating an EJB, or deleting an EJB. When deployed, these interfaces are used to create classes for containers, so that clients can delete or create and locate related operations. The system communicates with the front-end representation layer mainly through session beans, where user login information is stored by the bean and data requests, such as where user class selection information is recorded and stored. The information layer of the user's operation is also done by the entity bean, the backend data information is also mapped by the bean, and some functions required by the system such as creation, deletion, or query are also defined by the bean. There are three main types of entities in the system, one is the teacher entity, the other is the student entity, and the other is the course entity. Asynchronous information processing is done through the driver bean, which mainly sends course announcements or notifications to each entity.

\section{Conclusion}

In this paper, we study the theory and implementation of J2EE technology and discuss web services, MVC, and B/S architecture model. In the application direction of the research of this topic and the foothold of the research and development, first of all, the current research and development status of web teaching and multimedia technology is analyzed in a relevant way, and on this basis, the tools and the specific scheme to be developed in this paper are proposed. The overall design of the system is based on the actual needs of online English teaching in China, and the design of the main functional modules of the system is established. The application of the $\mathrm{B} / \mathrm{S}$ mode application model is studied and researched, and the system functional modules are divided based on the system requirement analysis. Based on J2EE technology, detailed development in the web layer, business logic layer, and data layer was developed, and each functional module of the system was implemented. In order to increase students' interest in learning, a teaching system interface with a high degree of affinity was designed. The services provided by the system allow for on-demand and simultaneous broadcasting of video material. Some research has been done on the data exchange technology of multimedia database, and efforts have been made to realize its application value. In the research study process of this paper, it is necessary to apply a lot of computer software technology and to have a high level of research on software engineering-related courses, especially on object-oriented programming methods, whose program structure is a collection of classes and a structure linked by inheritance relations between all kinds, with a main program in which each object is defined and the laws of passing messages between them are specified. Due to the author's lack of expertise, limited time for professional practice, and the constraints of working conditions, there are bound to be problems of one kind or another in the design and implementation of this system, and it is hoped that this will be addressed in future studies. In the future, we will borrow the understanding of testing from the teacher in the software testing class: software testing is a very apprehensive process in the software development process.

\section{Data Availability}

The data used to support the findings of this study are available from the corresponding author upon request.

\section{Conflicts of Interest}

The authors declare that they have no known competing financial interests or personal relationships that could have appeared to influence the work reported in this paper.

\section{Acknowledgments}

This work was supported by the Anhui Provincial Education Quality Engineering Project under grant no. 2019jyxm0230.

\section{References}

[1] J. Cheng and L. Wei, "Individual agency and changing language education policy in China: reactions to the new 'Guidelines on College English Teaching,', Current issues in language planning, vol. 22, no. 1-2, pp. 117-135, 2021.

[2] Y. Huang, College of Foreign Languages, Nanjing University of Aeronautics and Astronautics, Nanjing, Jiangsu, China, Y. Wang, and F. Ye, "A study of the application of word cloud visualization in College English Teaching," International Journal of Information and Education Technology, vol. 9, no. 2, pp. 119-122, 2019.

[3] Q. Liang, "An empirical study on the effectiveness of multimedia annotation to the news listening comprehension," Higher education of social science, vol. 19, no. 1, pp. 70-74, 2020. 
[4] L. Mao, "Application of browser/server architecture in college English online learning system design," International Journal of Emerging Technologies in Learning (iJET), vol. 13, no. 3, pp. 129-140, 2018.

[5] Y. Shu, "Experimental data analysis of college English teaching based on computer multimedia technology," Computer aided design and applications, vol. 17, Supplement 2, pp. 46-56, 2020.

[6] Y. Yi and W. Dan, "The realization of ideological and political education in college English based on cultural confidence," Creative Education, vol. 11, no. 11, pp. 2193-2198, 2020.

[7] W. Zhang and C. Zhu, "Comparing learning outcomes of blended learning and traditional face-to-face learning of university students in ESL courses," International journal on $e$ learning, vol. 17, no. 2, pp. 251-273, 2018.

[8] X. Zhao, "Mobile english teaching system based on adaptive algorithm," International journal of emerging technologies in learning (ijet), vol. 13, no. 8, pp. 64-77, 2018.

[9] X. Zhu, "Teaching Chinese culture in college English classes in the context of outreaching strategy," Theory and practice in language studies, vol. 9, no. 7, pp. 870-877, 2019.

[10] X. Tan, "On reform of college English teaching based on the FiF smart learning platform," Journal of language teaching and research, vol. 10, no. 5, pp. 1067-1072, 2019.

[11] A. Turnbull and R. Turnbull, "Rights, wrongs, and remedies for inclusive education for students with significant support needs: professional development, research, and policy reform," The Journal of the Association for Persons With Severe Handicaps, vol. 45, no. 1, pp. 56-62, 2001.

[12] J. S. Rubin, R. M. Good, and M. Fine, "Parental action and neoliberal education reform: crafting a research agenda," Journal of Urban Affairs, vol. 42, no. 4, pp. 492-510, 2020.

[13] E. I. Mora and D. J. Greenwood, "Part 1: active learning and intercultural competence: action research reform of a US study abroad programme in Seville, Spain," Learning and teaching, vol. 12, no. 3, pp. 11-17, 2019.

[14] P. M-m, "New mandates for reform of China's research infrastructure," National Science Review, vol. 5, no. 4, pp. 443-443, 2018.

[15] E. Nelson and J. Charteris, "Student voice research as a technology of reform in neoliberal times," Pedagogy culture and society, vol. 29, no. 2, pp. 213-230, 2021.

[16] J. A. Birt, M. Khajeloo, C. C. Rega-Brodsky et al., "Fostering agency to overcome barriers in college science teaching: going against the grain to enact reform-based ideas," Science education, vol. 103, no. 4, pp. 770-798, 2019.

[17] L. Wang, "Research and practice of reform on college English teaching under the environment of information technology," Theory and practice in language studies, vol. 10, no. 4, pp. 453-458, 2020.

[18] H. Chi, "Talents-oriented action on Chinese college English educational reform," Universal Journal of Educational Research, vol. 8, no. 4, pp. 1439-1444, 2020.

[19] S. Zhiyong, G. K. Sidhu, and P. Muthukrishnan, "College English language teaching reform and EFL lecturers' teaching practice: a case study in China," Universal Journal of Educational Research, vol. 8, no. 1, pp. 230-237, 2020.

[20] F. Jiang, "The reform of cultivation mode of Chinese university English translation talents in the age of artificial intelligence," Higher education of social science, vol. 18, no. 1, pp. 45-49, 2020 . 